\title{
Novos modelos de governo na universidade pública em Portugal e competitividade
}

\author{
Margarida Mano \\ Universidade de Coimbra \\ Maria da Conceição da Costa Marques \\ Instituto Superior de Contabilidade e Administração de Coimbra
}

\begin{abstract}
Em setembro de 2007, o novo regime jurídico das Instituições de Ensino Superior (RJIES), Lei no 62/2007, de 10 de setembro, introduziu um novo enquadramento de opções de modelos e estruturas de governação nas Instituições de Ensino Superior (IES) em Portugal. O ambiente externo de mudança, comum no contexto europeu, onde as IES adaptam suas acções estratégicas aos desafios da "Declaração de Lisboa", está na ordem do dia. O quadro de opções sobre modelos de governo e de gestão, que são cada vez mais discutidos numa perspectiva de competitividade, permite vantagens e reduz desvantagens comparativas em face das instituições privadas. Se, no contexto europeu, a concepção e o desenho de modelos de governo estão geralmente a convergir, esbatendo as diferenças entre o modelo de gestão das instituições privadas e públicas, em que medida a implementação dos modelos provoca mudanças visíveis no imediato em nível institucional? Em Portugal, a maioria das IES públicas optou pelo modelo tradicional, tendo visto já seus estatutos homologados e publicados em Diário da República. Apenas três instituições optaram pelo modelo fundacional. A presente investigação institucional visa analisar, a partir da metodologia de Clark, as alterações introduzidas nas IES públicas ao nível operacional e de gestão, no sentido de uma universidade empreendedora. Para o efeito, o estudo baseia-se na análise das opções institucionais que as IES enfrentam, ou seja, na possibilidade de escolha entre o tradicional quadro jurídico (direito público) e um novo quadro legal e organizacional (fundações públicas a operar sob o direito privado), a partir da análise dos estatutos entretanto já adotados. Pretende-se ainda integrar a perspectiva do olhar dos elementos externos que passaram recentemente, por via da lei, a integrar os órgãos máximos de governação das universidades públicas: os Conselhos Gerais. Neste artigo vamos efetuar uma análise crítica aos modelos de governo previstos em cada um dos estatutos das IES públicas, não deixando de fazer referência ao modelo fundacional.
\end{abstract}

Palavras-chave: ensino superior; universidade; modelos de governo; gestão.

New models of governance in the Public University in Portugal and competitiveness In September 2007, the new legal regime of the Institutions of Higher Education (RJIES), Law no $62 / 2007$ of 10 September, introduced a new framework of options for models and governance struc-

Artigo recebido em 15 jan. 2011 e aceito em 20 jul. 2011.

RAP - Rio de Janeiro 46(3):721-36, maio/jun. 2012 
tures in higher education institutions (HEIs) in Portugal. The external environment of change, common in Europe, where the IES adapt their actions to the strategic challenges of the 'Lisbon Declaration', is on the agenda. The framework of options for models of governance and management, which are increasingly discussed in terms of competitiveness, reduce benefits and disadvantages compared with comparative private institutions. If in the European context, the conception and design of governance models are generally converging, blurring the differences between the management model of private and public institutions, to what extent does the implementation of the model result in immediate visible changes at institutional level? In Portugal, most public HEIs have opted for the traditional model, having already their statutes approved and published in the Diário da República. Only three institutions have opted for the foundation model. This institutional research aims to analyse, based on Clark's methodology, changes in public HEIs at operational and management level, aiming for an entrepreneurial university. For this purpose, the study is based on the analysis of institutional options that HEIs face, i.e. the possibility to choose between the traditional legal framework (public law) and a new legal and organizational framework (public foundations operating under private law) based on the analysis of the Statutes now adopted. It is also looking to integrate the perspective of the external elements that complying with the law recently were included in the top governance bodies of public universities: the General Council. In this article we make a critical analysis of governance models provided for in each of the statutes of the public HEIs, while also referring to the foundation model.

KEY WORDs: higher education; university; governance models; management.

\section{Introdução}

Recentemente, com a Lei no 62/2007, de 10 de setembro, foi aprovado o Regime Jurídico das Instituições de Ensino Superior (RJIES), que determina a reestruturação da estrutura orgânica e de poder interno na universidade. O modo de governação da universidade em Portugal transforma-se, por esta via, profundamente. Os órgãos de governo passam a ser o conselho geral - órgão colegial com representação interna e externa - e o reitor. O Senado passa a ser opcional e puramente consultivo. O reitor vê seus poderes amplamente reforçados.

No modelo subjacente à nova forma de governo estão princípios de gestão que tenderão a conduzir a maior eficiência e eficácia. Subsistem, contudo, ainda muitas dúvidas num modelo não experimentado, nomeadamente qual das alternativas previstas na mencionada lei - universidade pública e fundação pública - concorrerá para se atingirem maiores níveis de eficiência. No todo, fica mais fácil a introdução de mudanças sem se perder o essencial do controle democrático da vida universitária.

Neste artigo, pretende-se abordar a questão de saber em que medida o novo modelo de governação do sistema universitário português representa, por via do RJIES, um estímulo externo importante no sentido da transformação empreendedora para as universidades portuguesas.

Nesta fase inicial, de implementação das reformas, é exatamente na vertente da análise de algumas das condições assumidas pelas universidades nos processos estatutários, nomeadamente ao nível de: conceito de missão e critérios de desempenho claros em toda a 
organização; corpo directivo forte - combinação de uma direcção central forte, com fortes direcções das unidades e uma estrutura de relações colegiais clara —; escola autodireccionada e autoconfiante, que se apresenta o presente estudo, desenvolvido no âmbito do processo exploratório da investigação em curso.

\section{Caracterização dos modelos de governo da universidade}

A universidade europeia, originariamente, assentava em quatro modelos distintos. Na atualidade, como resultado de condições políticas, da crescente internacionalização e, principalmente, das exigências duma economia cada vez mais interdependente, na opinião de Mora e Bricall, citados por Michavila e Calvo (1998:33), convergem os seguintes modelos:

v O estilo napoleônico, em que as instituições universitárias são públicas, dependentes da administração central, financiadas pelo Estado, essencialmente docentes, embora a função investigadora seja tida em conta. Esse sistema é o que tradicionalmente se adota em França e em todos os países latinos.

、 O estilo anglo-saxônico, que põe a ênfase nos alunos, para que obtenham a formação mais completa possível. Propõe o regime de internato, tendo os Colleges uma importância especial, e as tutorias como entidades que asseguram a convivência e o decurso dos estudos. É seguido pela Grã-Bretanha, Estados Unidos da América e países que adotam sua cultura.

- O estilo de tradição alemã, conhecido como estilo humboldtiano, evidenciou-se pela precoce assimilação, no século passado, da nova ciência experimental. Segundo esse modelo, as universidades devem basear-se na liberdade acadêmica e a própria autoalimentação da ciência é gerada pelos professores de modo desinteressado e autônomo.

Nos países do Leste e Centro da Europa desenvolveu-se, até ao desmembramento da URSS, e como consequência do modelo de vida e governo soviéticos, um sistema universitário, no qual os ministérios exerciam a tutela sobre as diferentes carreiras. As universidades estavam e ainda permanecem especializadas, não para reduzir o número de alunos, mas pela distinta dependência funcional. A investigação não era assunto fundamental para as universidades, mas sim responsabilidade das academias de investigação.

Na década de 1950, as universidades europeias seguiam mais ou menos um destes modelos e as funções desempenhadas por seus diplomados (profissionais liberais, serviços da administração) estavam de acordo com as procuras sociais da época. As universidades tinham a possibilidade de prever a procura social do ensino que ministravam.

Até à década de 1970, verificou-se uma mudança radical, determinando novas formas de relacionamento entre a universidade e a comunidade. Esse fato deveu-se ao desenvolvimento econômico da Europa após a Segunda Guerra Mundial, às alterações demográficas, às mudanças de ideologia e ao aumento do estado de bem-estar. Por conseguinte, é nas décadas de 1960 e 1970 que a universidade se identifica em seus fins com a criação de uma verdadeira 
democracia social. Como consequência, surge a necessidade de uma universidade de massas, sem precedente nos oito séculos anteriores.

Na década de 1980 surgem novas mudanças na relação universidade/sociedade (Mora, 2001:5). A crise econômica dos anos 1970 e o predomínio de outras necessidades sociais, como a saúde e a segurança social, dão à sociedade a ideia de que a universidade goza de privilégios exagerados e que é preciso rever o modelo de financiamento.

Surge assim outro modelo, apelidado de neoliberal, no qual os governos, em nome da sociedade e das restrições orçamentais, desafiam as universidades "a desfazer os seus laços históricos com os Estados, e a substituírem na mente dos estudantes, dos professores e dos gestores universitários a ideia de serviço estatal pela ideia de sensibilização às procuras do mercado" (Neave, citado por Michavila e Calvo, 1998:35). Essa modificação ocorre sobretudo nos países anglo-saxônicos, de modo cordato nos Estados Unidos da América e de forma autoritária na Grã-Bretanha.

Nos anos 1990 entra-se numa terceira etapa, caracterizada pela procura de novas formas de relacionamento entre o poder político e o acadêmico. Michavila e Calvo (1998:35) defendem que essa época não se concluiu na Europa. Além dos problemas postos pela sociedade, outros surgiram como as opções políticas, a escassez de financiamentos e a massificação, ao lado de outros, também importantes, como a internacionalização, com seu inevitável mimetismo de gestão, a variação da procura, as novas tecnologias, que exigem mudanças curriculares e substanciais aumentos de financiamento etc.

A evolução global da vida universitária tem sido influenciada por diferentes fatores. No caso dos sistemas universitários públicos, estes estão submetidos historicamente a duas forças opostas: o controle do Estado e a autonomia universitária. E as universidades, constituídas em unidades produtivas, passaram a estar subordinadas a uma terceira força, a força do mercado, onde se verifica uma relação entre os que oferecem o produto e os que o procuram (Rodríguez Prieto e Álvarez Pérez, 2002:284).

Em Portugal, nos últimos tempos, verifica-se que a forma como tem vindo a ser encarado o relacionamento universidade-empresa se alterou bastante. Basta recuar no tempo e verificar a dificuldade de diálogo entre empresas e instituições universitárias. As primeiras acentuavam a crítica a um demasiado teoricismo e à falta de adesão à realidade nacional, enquanto as segundas se lamentavam da falta de competências e de modernidade do tecido econômico do país. Se bem que ainda possam existir "ilhas", a realidade é hoje diferente e sente-se que algo começa a mudar. Menezes (2003:19) defende: "torna-se imperioso definir projetos nacionais que permitam a acumulação de competências e a sofisticação tecnológica em clusters industriais com potencial competitivo internacional de forma a alterar o nosso modelo de desenvolvimento".

Quanto à qualidade dos sistemas universitários, trata-se de um problema pertinente e atual, que se coloca quando se tem de prestar contas e os governos cerceiam os financiamentos, ainda que as exigências sejam cada vez maiores. O problema da qualidade inscreve-se no quadro geral das diferentes políticas para o qual têm sido adotadas soluções diversas, mesmo 
que convergentes. O destaque que é dado atualmente à qualidade exige que tratemos o assunto de modo particular.

Álvarez (2002:45) defende que as universidades constituem realmente centros de produção de serviços sociais e intangíveis, e vêm a ser fontes de riqueza econômica em si mesmas. Convém ainda ter presente que, para além desse efeito econômico direto, a formação de capital humano que desempenha através de sua atividade docente tem uma consequência muito importante a médio e longo prazo sobre a capacidade produtiva e a competitividade econômica de sua envolvente. Esta realidade exerce-se fundamentalmente ao nível local e regional onde as universidades estão inseridas, se bem que numa sociedade globalizada como a atual, os efeitos e as sinergias podem ser muito mais amplos.

Costa (2003) identifica três modelos de governação universitária: dois típicos (o velho modelo corporativo/colegial europeu continental e o modelo americano, seguido também em grande parte no Japão, nos países asiáticos do pós-guerra e, com maiores ou menores desvios, também no Reino Unido e em seus domínios); e um atípico (o "novo" modelo europeu), mas nem por isso de menor potencialidade e certamente de maior flexibilidade. Esse novo modelo europeu, relativamente recente, com um misto do modelo americano e da tradição europeia, foi designado modelo de governação partilhada.

O primeiro modelo típico é o modelo corporativo/colegial, e, tal como aconteceu em Portugal, está em franco declínio. Esse modelo assenta em pressupostos ideológicos de "gestão democrática", vingou depois das transformações democráticas (e de alguns dos seus excessos) na Itália do pós-guerra e, mais recentemente, em Portugal, Espanha e Grécia. Idênticas razões conduzem a alguns afloramentos desse modelo nos países de Leste, embora compensados por seu fascínio atual pela sociedade americana.

O modelo americano é relativamente típico, apesar da grande diversidade das instituições (colégios comunitários, universidades de ensino, universidades de investigação, universidades estatais e privadas), tendo vindo a sofrer algumas modificações originadas pela emergência do novo tipo de universidades empresariais (for-profit universities e corporate universities).

O modelo europeu de governação partilhada é recente (com exceção do Reino Unido e da Irlanda), havendo alguns países, nomeadamente os escandinavos, a Holanda e a Suíça, que desde há vários anos vinham a introduzir alguns valores e formas de atuação do modelo americano.

Com esse modelo pretende-se corrigir as insuficiências dos sistemas tradicionais europeus de governação, e, para isso, vai buscar soluções organizativas e funcionais à teoria moderna da organização e gestão institucionais ou ao funcionamento das universidades americanas de excelência. Mas, pela variedade dessas soluções e pelas diversas formas como têm sido adaptadas às realidades nacionais, o modelo não se pode definir de forma descritiva só por seus princípios e critérios.

O novo modelo em Portugal veio de algum modo assumir esta perspectiva num quadro de autonomia revista. 
Sobre esta temática, Amaral e Magalhães (2000:8) referem que o mercado surgiu como figura principal do discurso político quer ao nível do Estado quer ao nível das instituições, referindo que, embora lhes tenha concedido autonomia, mantém mão firme na regulação do ensino superior, dando origem ao que se pode chamar modelo híbrido de regulação.

Os mesmos autores, citando Van Vught, argumentam que as políticas de regulação estatal pela via dos mecanismos tipo mercado ainda não são claras, e que segundo David Dill não foi ainda provada a superioridade desses mecanismos sobre os mecanismos tradicionais de regulação pública.

Surge assim a figura dos stakeholders - representantes dos vários interesses que convivem com a universidade - , em sua estrutura de governação, no sentido de serem dadas respostas adequadas ao mundo exterior e de tornar as instituições mais relevantes.

A participação de representantes de interesses sociais exteriores às instituições de ensino superior nos corpos de governação das universidades públicas pode ser vista no RJIES por meio da participação de entidades externas no Conselho Geral.

\section{A metodologia de Clark}

O enquadramento do sistema de ensino superior e das "forças" que influenciam suas instituições encontra no célebre "Triângulo de Coordenação" (Clark, 1983) um modelo representativo claro e ainda hoje uma referência básica adequada, apesar da constante dinâmica relacional. ${ }^{1}$

Estado, mercado e oligarquia acadêmica são os três vértices do triângulo de influências que coordenam e controlam, de forma e em proporções variadas, os atores institucionais do ensino superior nas últimas décadas.

A cada um dos vértices corresponderá um modelo ideal de organização que Lars Niklasson (1995:347) tipifica em government agency; private company e self-ruling monastery. Os três modelos representam parcerias de padrões de governação claramente distintos, respectivamente:

v Governo burocrático, em que as regras externas são fortemente determinantes e onde o planeamento decorre de uma avaliação ex ante muito importante;

- Governo baseado em práticas de gestão, em que as principais regras são estabelecidas à entrada e onde o mercado é o principal palco de avaliação da performance da instituição;

、 Governo de decisão colegial com regras internas muito fortes e em que a avaliação assenta em princípios de colegialidade e de conhecimento (Peer Review).

\footnotetext{
${ }^{1}$ Clark (1998) posteriormente introduz uma nova categoria no modelo: “organização”. A organização interage de perto com a liderança, a gestão, a governação. Veja-se, a propósito dessa ideia, duas abordagens distintas por Schimak em Braun e Merrien (1999:179-194) e Sporn (1999:15-20).
} 
Muito se pode ler sobre a cultura empreendedora como paradigmática de uma época de massificação, de abertura e de globalização, em particular no ensino superior. Essa cultura é frequentemente apresentada como o modelo de sucesso ou de referência para a mudança, o que provoca reações nem sempre em sintonia entre os que, valorizando o contexto presente, se identificam com o modelo acreditando que os atuais paradigmas do mercado e da globalização conduzem à inevitabilidade de um novo conceito de escola, e aqueles para quem, pelo contrário, a escola representando uma referência de estabilidade pública, veem na cultura empreendedora uma moda e não uma referência.

Clark (1998:5) defende que as universidades, por meio da sua ação empreendedora, podem se transformar: "Five elements constitute an irreductible minimum: a strengthened steering core; an expended development periphery; a diversified funding base; a stimulated academic heartland; and an integrated entrepreneurial culture". ${ }^{2}$ Neste contexto, Clark desenvolve sucessivamente ao longo da sua obra (Clark, 1998, 2000, 2001) a ideia de que a universidade empreendedora corresponde a um reforço da colegialidade, da autonomia e de sua realização como universidade.

A mudança é uma necessidade para as universidades que pretendem ser viáveis e competitivas, num mundo global do conhecimento, que decorre fundamentalmente de duas ordens de razões:

จ A limitação sentida pela universidade pública em responder à procura crescente, em face de suas estruturas internas tradicionalmente rígidas, adequadas a um ensino superior de elite;

- A homogeneização, promovida pelos Estados, em nível nacional, no processo de descentralização que retira às universidades margem de "criatividade" e risco em nível organizacional.

Em OECD (2001) encontramos uma abordagem cruzada de vários autores ${ }^{3}$ relativamente às características fundamentais do empreendedorismo colegial, isto é, como a cultura colegial se pode transformar numa cultura empreendedora. Dessas características destacam-se aquelas que de algum modo estão mais proximamente ligadas com o conceito de governação:

v Conceito de missão e critérios de desempenho claros em toda a organização;

v Corpo diretivo forte: combinação de uma direção central forte, com fortes direções das unidades, e uma estrutura de relações colegiais clara. A direção deve conseguir combinar os valores tradicionais com os valores empreendedores;

\footnotetext{
2 Tradução livre: "Cinco elementos constituem um mínimo irredutível: um corpo diretivo forte, gastos de desenvolvimento na periferia, uma base diversificada de financiamento, um staff acadêmico estimulado e uma cultura empreendedora integrada".

${ }^{3}$ John Davies; José-Ginés Mora e Enrique Villarreal; Pierre Daumand e Jamil Salmi, entre outros.
} 
- Base de financiamento diversificada: além dos fundos governamentais, é importante obter uma terceira fonte de rendimento, constituída por outras fontes governamentais, fontes privadas e financiamento gerado na escola;

- Escola autodirecionada e autoconfiante: utiliza a colegialidade, no que é o essencial da sua atividade (conhecimento; ensino/investigação), no aproveitamento de oportunidades, como motor de mudança. A organização e a gestão da organização devem assentar em princípios de eficiência e eficácia, com estruturas profissionalizadas;

、 Desenvolvimento de parcerias interinstitucionais: o tipo de acordos/parcerias que a escola estabelece com os stakeholders revela muito do seu caráter empreendedor. As parcerias terão de levar em conta as diferentes culturas institucionais;

、 Estrutura organizacional com tendência para o desenvolvimento de unidades periféricas fora das unidades tradicionais, que traduzem o despertar para as oportunidades do mercado em termos de captação de recursos e encorajam formas diferentes de trabalhar.

Apesar da existência de algumas barreiras estruturais - ao nível da relação estabelecida entre a escola e o Estado, de que são exemplo sistemas administrativos de avaliação, mas também ao nível interno de estruturas colegiais de poder —, ou por causa destas barreiras, existe na escola em Portugal uma percepção muito forte da necessidade de ter capacidade de adaptação, empreendedora, num contexto cada vez menos estável, que exige a mudança contínua. A mudança é para a escola uma inevitabilidade "ecológica" em face das alterações ambientais.

\section{Modelos de governação previstos no RJIES}

Com a publicação do RJIES são introduzidas profundas alterações nos modelos de governo das instituições universitárias, um processo que ainda não se encontra totalmente concluído. No que diz respeito ao governo das instituições, o RJIES fortalece as condições de governabilidade das instituições universitárias, na medida em que diferencia o grau de responsabilidade dos diferentes corpos (docentes, estudantes e funcionários) em sua gestão. Reforça os poderes e responsabilidades dos reitores e esbate as tendências corporativas, ao incluir membros externos no Conselho Geral das universidades. No conjunto, fica mais fácil incluir dinâmicas de mudança.

É, no entanto, difícil prever o grau de comprometimento dos cooptados externos com a universidade, por não existir experiência prévia em Portugal nesse domínio. Seu envolvimento pode passar por se lhes fazer sentir que desempenham um papel relevante na vida das instituições.

Sobre a aplicação do RJIES, alguns passos importantes foram entretanto dados, acerca dos quais se dá conta nos pontos que se seguem. 


\subsection{Direção central}

A implementação de conselhos nas universidades europeias é muito recente se comparada com a experiência dos Estados Unidos da América. Mesmo se em alguns países, como é o caso da Inglaterra, a experiência já tem décadas, os efeitos da implementação dos conselhos na Europa em matéria de governação institucional ainda não estão totalmente compreendidos. Um estudo comparativo (Machado, Taylor e Peterson, 2008) da Áustria, Suécia, Noruega e Holanda mostra que os conselhos são em geral pequenos (cinco a 15 membros), já com os representantes externos incluídos.

Em Portugal, o RJIES criou um conselho geral com um número de membros compreendido entre 15 e 35 membros, com pelo menos $30 \%$ de membros externos. O princípio de escolha dos membros é a eleição. Numa primeira fase há na universidade a eleição dos membros internos, em que a presença de acadêmicos e investigadores deve representar mais de $50 \%$ do total. Numa segunda fase os membros internos cooptam os membros externos.

A análise dos estatutos das universidades portuguesas revela uma dimensão média do conselho que se situa nos 26 membros, com um mínimo de 15 numa universidade e máximo de 35 em duas universidades, não parecendo que a dimensão esteja dependente do tamanho e da complexidade da instituição.

A presença de membros externos nos conselhos das universidades europeias assume perspectivas e dimensões diferentes. Em algumas universidades os stakeholders externos são membros exclusivos do conselho (ex.: NTH - Utrecht), noutras representam 50\% dos membros (ex.: SW - Uppsala; AU - Vienna), podendo ser nomeados pelo ministro ou cooptados pelos membros. No caso português, as universidades decidiram uma presença de membros externos que varia entre um mínimo de $26 \%$ (Universidades de Aveiro, Porto, Lisboa, Minho e Trás-os-Montes) e o máximo legal de 30\% (ISCTE, Universidades da Madeira, Nova de Lisboa e Técnica de Lisboa). Nesse contexto, a natureza fundacional não parece relevar para a distinção da dimensão da representação externa.

As universidades públicas portuguesas parecem ainda tender a serem conservadoras, garantindo uma transição de representatividade para todos os corpos que no sistema anterior estavam representados nos órgãos de decisão colectivos (staff e estudantes). Apenas duas universidades (Madeira e Nova de Lisboa) eliminaram a representação do staff, continuando as outras com a representação desse corpo até um peso máximo de 8\% (Universidade de Évora).

\subsection{Direções das unidades}

O RJIES prevê, relativamente à estrutura orgânica das universidades, a possibilidade de existirem estruturas (faculdades/departamentos/...) que podem ter (ou não, no caso das fundações) órgãos de governo. Apenas a Universidade do Porto prevê a possibilidade de existirem unidades orgânicas sem órgãos de governo. Relativamente ao modo de escolha dos responsá- 
veis das unidades orgânicas, apenas duas universidades (Aveiro e Aberta) optaram pela nomeação pelo reitor dos diretores das unidades, tendo todas as outras decidido a via da eleição no âmbito da unidade orgânica para a escolha do diretor.

\subsection{Colegialidade}

Em que medida esta nova tendência europeia, com a implementação de um conselho geral, com reforço de membros externos, enfraquece a colegialidade?

O facto de o RJIES estabelecer um mínimo de 50\% de membros acadêmicos e investigadores no Conselho significa que a academia terá o controle sobre o órgão. Assim, o princípio da colegialidade parece ter sido conseguido ao mais alto nível.

Da análise dos estatutos verifica-se que as universidades asseguraram uma participação de acadêmicos que varia entre 51\% (Universidades do Algarve e Coimbra) e 57\% (Universidades de Trás-os-Montes e Alto Douro).

O quadro seguinte reflete a situação exposta.

\section{Organização do Conselho Geral}

\begin{tabular}{|c|c|c|c|c|c|c|c|c|c|}
\hline \multicolumn{10}{|c|}{ CONSELHO GERAL } \\
\hline Universidade & $\begin{array}{l}\text { Professores e } \\
\text { Investigadores }\end{array}$ & $\%$ & Estudantes & $\%$ & $\begin{array}{c}\text { Não } \\
\text { Docentes }\end{array}$ & $\%$ & Externos & $\%$ & Total \\
\hline U. Açores & 8 & $53 \%$ & 2 & $13 \%$ & 1 & $7 \%$ & 4 & $27 \%$ & 15 \\
\hline U Aveiro & 10 & $53 \%$ & 3 & $16 \%$ & 1 & $5 \%$ & 5 & $26 \%$ & 19 \\
\hline U. Porto & 12 & $52 \%$ & 4 & $17 \%$ & 1 & $4 \%$ & 6 & $26 \%$ & 23 \\
\hline ISCTE & 17 & $52 \%$ & 5 & $15 \%$ & 1 & $3 \%$ & 10 & $30 \%$ & 33 \\
\hline U. Aberta & 12 & $55 \%$ & 3 & $14 \%$ & 1 & $5 \%$ & 6 & $27 \%$ & 22 \\
\hline U. Algarve & 18 & $51 \%$ & 6 & $17 \%$ & 1 & $3 \%$ & 10 & $29 \%$ & 35 \\
\hline UBI & 15 & $52 \%$ & 5 & $17 \%$ & 1 & $3 \%$ & 8 & $28 \%$ & 29 \\
\hline U. Coimbra & 18 & $51 \%$ & 5 & $14 \%$ & 2 & $6 \%$ & 10 & $29 \%$ & 35 \\
\hline U. Évora & 13 & $52 \%$ & 3 & $12 \%$ & 2 & $8 \%$ & 7 & $28 \%$ & 25 \\
\hline U. Lisboa & 12 & $52 \%$ & 4 & $17 \%$ & 1 & $4 \%$ & 6 & $26 \%$ & 23 \\
\hline U. Madeira & 11 & $55 \%$ & 3 & $15 \%$ & & $0 \%$ & 6 & $30 \%$ & 20 \\
\hline U. Minho & 12 & $52 \%$ & 4 & $17 \%$ & 1 & $4 \%$ & 6 & $26 \%$ & 23 \\
\hline U. Nova L. & 11 & $55 \%$ & 3 & $15 \%$ & & $0 \%$ & 6 & $30 \%$ & 20 \\
\hline U. Técnica L. & 14 & $52 \%$ & 4 & $15 \%$ & 1 & $4 \%$ & 8 & $30 \%$ & 27 \\
\hline Utad & 13 & $57 \%$ & 3 & $13 \%$ & 1 & $4 \%$ & 6 & $26 \%$ & 23 \\
\hline Média & 13 & $53 \%$ & 4 & $15 \%$ & 1 & $4 \%$ & 7 & $28 \%$ & 25 \\
\hline
\end{tabular}

Fonte: Autores. 
A colegialidade é assegurada nas escolas ao nível da escolha dos diretores e dos órgãos científicos e pedagógicos. A colegialidade é ainda inerente ao modelo de escolha dos dirigentes das unidades orgânicas pela grande maioria das universidades, com um reforço do envolvimento das estruturas acadêmicas de forma descentralizada.

\subsection{Organização e gestão assentes em princípios de eficiência e eficácia}

Os estatutos de todas as universidades referem explicitamente as expressões "eficácia”, "eficiência" e "eficácia e eficiência", tal como se apresenta no quadro seguinte. Embora em contextos diferentes, há também preocupações com a partilha de recursos e serviços, visando assim ganhar as escolas e garantir sua eficiência, mediante a criação de centros de serviços partilhados nas universidades onde tradicionalmente todas ou algumas unidades orgânicas têm autonomia administrativa e financeira, como é o caso da Universidade do Porto, da Universidade de Coimbra e da Universidade de Lisboa.

Quadro 2

\section{Estatutos das universidades}

\begin{tabular}{|c|c|c|}
\hline \multirow{2}{*}{$\begin{array}{l}\text { Universidades (Estatutos } \\
\text { aprovados) }\end{array}$} & \multicolumn{2}{|c|}{ Algumas Características } \\
\hline & $\begin{array}{c}\text { Serviços Partilhados/Recursos e Serviços } \\
\text { Partilhados/Centros de Serviços } \\
\text { Partilhados }\end{array}$ & $\begin{array}{c}\text { Eficácia } \\
\text { Eficiência } \\
\text { Eficácia e Eficiência }\end{array}$ \\
\hline $\begin{array}{l}\text { U. Aveiro } \\
\text { DN 18-A/2009, 14-5 } \\
\text { Modelo fundacional: DL 95/2009, } \\
27-4\end{array}$ & Arts. $2 / 3$ I) e $38 / 3$ & Arts. $23 / 3$ d), 45/2, 46/1 e 47/2 \\
\hline $\begin{array}{l}\text { U. Porto } \\
\text { DN 18-B/2009, 14-5 } \\
\text { Modelo fundacional: DL 96/2009, } \\
27-4\end{array}$ & $\begin{array}{l}\text { Arts. 16/1 a) e b), } 20 \text { b), } 94 \text { a } 97 \text { e 108/2 } \\
\text { d) }\end{array}$ & Arts. $14 / 3$ c), 16/1 a) e b) e 40/1 e) \\
\hline $\begin{array}{l}\text { ISCTE } \\
\text { DN 18/2009, 8-5 } \\
\text { Modelo fundacional: DL 97/2009, } \\
27-4\end{array}$ & & Arts. $2 / 3,11$ c), 30/1 h), 34/1 e 105/1 III) \\
\hline $\begin{array}{l}\text { U. Aberta } \\
\text { DN 65-B/2008, 22-12 }\end{array}$ & & Art. 37/1 e) \\
\hline $\begin{array}{l}\text { U. Açores } \\
\text { DN 65-A/2008, 22-12 }\end{array}$ & & Art.s 19 e 95 c) \\
\hline $\begin{array}{l}\text { U. Algarve } \\
\text { DN 65/2008, 22-12 }\end{array}$ & Arts. $12 / 1$ e $56 / 1$ & Artss 33/1 g) e 56/1 \\
\hline
\end{tabular}




\begin{tabular}{|c|c|c|}
\hline \multirow[b]{2}{*}{$\begin{array}{l}\text { Universidades (Estatutos } \\
\text { aprovados) }\end{array}$} & \multicolumn{2}{|c|}{ Algumas Características } \\
\hline & $\begin{array}{c}\text { Serviços Partilhados/Recursos e Serviços } \\
\text { Partilhados/Centros de Serviços } \\
\text { Partilhados }\end{array}$ & $\begin{array}{c}\text { Eficácia } \\
\text { Eficiência } \\
\text { Eficácia e Eficiência }\end{array}$ \\
\hline $\begin{array}{l}\text { U. Beira Interior } \\
\text { DN 45/2008, 1-9 }\end{array}$ & & Art. 24/1 e) \\
\hline $\begin{array}{l}\text { U. Coimbra } \\
\text { DN 43/2008, 1-9 }\end{array}$ & Arts. $12 / 1,27 / 2$ e $69 / 1$ & Arts, 27/2, 49/1 I) e 69/1 \\
\hline $\begin{array}{l}\text { U. Évora } \\
\text { DN 54/2008, 20-10 }\end{array}$ & & Art. 22/1 f) \\
\hline $\begin{array}{l}\text { U. Lisboa } \\
\text { DN 36/2008, 1-8 }\end{array}$ & Arts. 33/2, 34/3 e 3/1 c) no Apêndice & Arts. $31 / 1$ g) e $45 / 1$ \\
\hline $\begin{array}{l}\text { U. Madeira } \\
\text { DN 42/2008, 26-8 }\end{array}$ & & Arts. $27 / 1 \mathrm{~g}$ ) e $29 / 6$ \\
\hline $\begin{array}{l}\text { U. Minho } \\
\text { DN 61/2008, 5-2 }\end{array}$ & & Art.s 3/3, 18/2 and 48/1 \\
\hline $\begin{array}{l}\text { U. Nova Lisboa } \\
\text { DN 42/2008, 26-8 }\end{array}$ & & Arts. $10 / 1$ h), 30 b) e $72 / 6$ \\
\hline $\begin{array}{l}\text { U. Técnica Lisboa } \\
\text { DN 57/2008, 6-11 }\end{array}$ & $\begin{array}{l}\text { no } 3 \text { do preâmbulo (recursos humanos e } \\
\text { financeiros partilhados) }\end{array}$ & $\begin{array}{l}\text { no } 4 \text { b) do preâmbulo (eficiência no uso } \\
\text { dos recursos humanos e materiais), } 29 / 2 \\
\text { i), j) e K) }\end{array}$ \\
\hline $\begin{array}{l}\text { U. Trás-os-Montes e Alto Douro } \\
\text { DN 63/2008, 9-12 }\end{array}$ & Art. $9 / 3$ & Arts. $48 / 1$ e) e $3,86 / 1,97 / 1$ c) e $112 / 4$ \\
\hline
\end{tabular}

Fonte: Autores.

A diminuição em termos reais do financiamento do ensino superior a que se tem assistido, por parte do Estado, não pode deixar de constituir um fator de preocupação. Diversas medidas de racionalização têm sido postas em prática pelas instituições de ensino superior, muitas vezes seguindo uma lógica de mercado, cujos efeitos se têm feito sentir, conforme demonstra o quadro de "Vendas e Prestações de Serviços consolidados" (VPS) das universidades que prestam contas consolidadas e a que se teve acesso. Assim:

\section{Quadro 3}

\section{Vendas e prestações de serviços}

\begin{tabular}{|c|c|c|c|c|c|c|}
\hline \multirow{3}{*}{ Universidade } & \multicolumn{6}{|c|}{ Ano económico } \\
\hline & \multicolumn{2}{|c|}{2006} & \multirow[t]{2}{*}{$\%$} & \multicolumn{2}{|c|}{2007} & $\%$ \\
\hline & Total VPS & Total Proveitos & & Total VPS & Total Proveitos & \\
\hline Algarve & 3.049 .095 & 56.556 .252 & $5,39 \%$ & 3.169 .616 & 54.562 .171 & $5,81 \%$ \\
\hline Aveiro & 6.028.719 & 86.912 .976 & $6,94 \%$ & $(*)$ & & \\
\hline
\end{tabular}




\begin{tabular}{|l|l|l|l|l|l|l|}
\hline \multirow{3}{*}{ Universidade } & \multicolumn{5}{c|}{ Ano económico } \\
\cline { 2 - 7 } & \multicolumn{2}{|c|}{2006} & $\%$ & \multicolumn{2}{c|}{2007} & \multicolumn{2}{c|}{$\%$} \\
\cline { 2 - 8 } & \multicolumn{1}{|c|}{ Total VPS } & Total Proveitos & & \multicolumn{1}{c|}{ Total VPS } & Total Proveitos & \\
\hline Beira Interior & 2.257 .344 & 35.363 .807 & $6,38 \%$ & 2.393 .642 & 39.483 .830 & $6,06 \%$ \\
\hline Coimbra & 9.676 .593 & 141.364 .061 & $6,85 \%$ & 10.559 .383 & 145.068 .835 & $7,28 \%$ \\
\hline Madeira & 325.225 & 15.941 .958 & $2,04 \%$ & 495.654 & 16.325 .827 & $3,04 \%$ \\
\hline Porto & 10.179 .383 & 180.686 .912 & $5,63 \%$ & 12.204 .983 & 176.597 .202 & $6,91 \%$ \\
\hline
\end{tabular}

(*) Não foi possível ter acesso às contas de 2007. Fonte: Autores.

Pode se constatar que no ano de 2007 as universidades de maior dimensão (Coimbra e Porto) aumentaram suas receitas próprias com origem em "vendas e prestações de serviços". Numa altura em que a universidade se vê forçada a desempenhar um papel crescente na prestação de serviços e na procura de fontes de financiamento alternativas, é muito natural que a tendência para a captação de receitas próprias venha a aumentar se as restrições ao nível do financiamento público se mantiverem.

\subsection{Natureza fundacional}

Não relevam diferenças nas condições de partida em termos das opções nas estruturas de poder e governação: nem ao nível do Conselho, nem ao nível das unidades orgânicas ou da colegialidade.

O enquadramento jurídico da "nova" fundação pública de direito privado universitária, sem tradição no nosso país, abrange aspectos basilares como o projeto da instituição, o programa de desenvolvimento, os estatutos da fundação, a estrutura orgânica e, mais importante, a nomeação do conselho de curadores pelo governo. As competências do conselho de curadores incluem poderes decisivos para a instituição, tais como a gestão patrimonial e financeira, a aprovação dos planos estratégicos e de atividade, os orçamentos etc.

As instituições que optarem pelo modelo fundacional deverão fundamentar a adoção do novo modelo de gestão e de enquadramento jurídico para a prossecução de seus objetivos, e deverão cumprir um conjunto de passos e regras, como sejam a apresentação de um estudo sobre as implicações dessa transformação institucional quanto à organização, gestão, financiamento e autonomia da instituição ou unidade orgânica.

As referidas instituições deverão também analisar as implicações que recaem sobre nomeações, exonerações, aquisição e alienação de patrimônio imobiliário, financiamento, operações de crédito. Essa análise deve também contemplar os planos estratégicos e os planos científico, pedagógico, financeiro e patrimonial, os planos anuais de atividades e apreciação do relatório anual das atividades da instituição. 
Veja-se, contudo, que a gestão privada, tão acarinhada pelos defensores do modelo, vem a par de uma considerável intervenção do governo (com a nomeação do conselho de curadores), com prejuízo para a autonomia universitária.

Num universo de 15 universidades, apenas três (Aveiro, Porto e ISCTE) se decidiram pela aplicação do artigo 177 do RJIES, ou seja, solicitaram a passagem ao regime fundacional.

Ao nível de vantagens, pode se dizer que o modelo fundacional representa menos burocracia, maior margem de decisão ao nível financeiro e de pessoal, embora conserve a orientação pública de sua missão, dados os limites à autonomia, representados pelo pagamento de propinas e pelo regime de acesso.

\section{Conclusões}

A multidiversidade de Clark pareceu retirar às universidades as características tradicionais de colegialidade. A universidade cosmopolita cresceu em alunos e em conhecimento, nem sempre tendo conseguido fazer as diferentes faculdades operar no conjunto universitário como um todo.

Este estudo exploratório corresponde a uma avaliação geral sobre o modo como o novo modelo de governação do sistema universitário português, por via do RJIES, representa um estímulo externo importante para a transformação da universidade portuguesa numa universidade empreendedora.

Nesta fase inicial do processo de mudança das universidades portuguesas relativamente às alterações do sistema de governação, foi feita a análise das condições assumidas pelas universidades nos processos estatutários, tendo-se concluído que as universidades parecem tender para o conservadorismo, garantindo uma transição de representatividade para todos os corpos que no sistema anterior figuravam nos órgãos de decisão colectivos (staff e estudantes).

Apenas duas universidades (Madeira e Nova de Lisboa) eliminaram a representação do staff, continuando as outras com a representação desse corpo até um peso máximo de $8 \%$ (Universidade de Évora). Por outro lado, da análise dos estatutos, conclui-se que as universidades asseguraram uma participação de acadêmicos que varia entre 51\% (Universidade de Algarve e Universidade de Coimbra) e 57\% (Utad).

Por sua vez, a colegialidade é afirmada nas escolas através da escolha dos diretores e dos órgãos científicos e pedagógicos. A colegialidade está ainda patente no modelo de escolha dos dirigentes das unidades orgânicas pela grande maioria das universidades, com um reforço do envolvimento das estruturas acadêmicas de forma descentralizada.

Na tentativa de colmatar a diminuição da comparticipação do orçamento do Estado, as universidades, seguindo por vezes uma lógica de mercado, procuram captar receitas próprias, prestando serviços à comunidade, entre outros. Através das contas consolidadas de algumas universidades, observou-se que no ano de 2007 as universidades de maior dimensão (Coimbra e Porto) aumentaram suas receitas próprias com origem em "vendas e prestações de serviços". 
Neste contexto, as universidades portuguesas parecem ter condições de governação de base, com o aproveitamento da oportunidade que o RJIES estimulou, alinhadas para um processo de mudança transformacional e empreendedora.

\section{Referências}

ÁLVAREZ, Jesús Lizcano. La contabilidad de gestión como instrumento para la mejora de la eficiencia en los centros universitarios. Revista Aeca, n. 60, Setúbal, Especial X Encuentro Aeca, 2002.

AMARAL, A.; MAGALHÃES, A. O conceito de stakeholder e o novo paradigma do ensino superior. Revista Portuguesa de Educação, v. 13, n. 2, p. 7-28, 2000.

AMARAL, A.; MAGALHÃES, A. Mapping out discourses on higher education governance. In: HUISMAN, J. (ed.). International perspectives on the governance of higher education alternative frameworks for coordination. New York/London: Routledge, 2009, p. 182-197.

BALDERSTON, Frederick E. Managing today's university: strategies for viability, change and excellence. San Francisco: Jossey-Bass Publishers, 1995.

BRAUN, D.; MERRIEN F.X. 1999. Governance of universities and modernisation of the State. In: BRAUN, D.; MERRIEN F.X. (Ed.). New managerialism and the governance of universities in a comparative perspective. London/Philadelphia: Jessica Kingsley Publishers, 1999. p. 9-33.

CLARK, Burton. Creating entrepreneurial universities: organizational pathways of transformation. Oxford: Pergamon-Elsevier Science, 1998.

CLARK, Burton. Collegial entrepreneurialism in proactive universities: lessons from Europe. Change, v. 32, n. 1, p. 10-19, Jan./Feb. 2000.

CLARK, Burton. The entrepreneurial university: new foundations for collegiality, autonomy, and achievement. Higher Education Management, v. 13, n. 2, p. 9-24, 2001.

CLARK, Burton. The higher education system: academic organization in cross-national perspective. Berkely/Los Angeles: University of California Press, 1983.

CLARK, Burton. University transformation: primary pathways to university autonomy, and achievement. In: BRINT, Steven (Ed.). The future of the city of intellect: the changing American university. Stanford: Stanford University Press, 2002.

COSTA, J. Vasconcelos. Equívocos e propostas sobre modelos de governação. 2003. Disponível em: $<$ http/pwp.netcabo.pt>. Acesso em: 31 jul. 2009.

KERR, C. The uses of the university. $3^{\text {rd }}$ ed. London: Harvard University Press, 1982.

LIZCANO ALVAREZ, Jesús. Los indicadores de gestión como instrumentos de transparencia y mejora en los ayuntamientos. Revista AECA, n. 61, p. 12-15, Sept./Dic. 2002. 
LÜTHJE, Christian; FRANKE, Nikolaus. Fostering entrepreneurship through university education and training: lessons from Massachusetts Institute of Technology. In: ANNUAL CONFERENCE ON: INNOVATIVE RESEARCH IN MANAGEMENT, 2ND. Euram. Stockholm, 2002.

MACHADO, M.L.; TAYLOR, J.S.; PETERSON, M. Leadership and strategic management: keys to institutional priorities and planning. European Journal of Education, v. 43, n. 3, p. 369-386, 2008.

MENEZES, João. A universidade num novo modelo de desenvolvimento. Semanário Económico, 31 jan. 2003.

MICHAVILA, Francisco; CALVO, Benjamín. La universidad española hoy - propuestas para una política universitaria. Madrid: Editorial Síntesis, SA. 1998.

MORA, José-Ginés. Governance and management in the new university. Tertiary Education and Management, n. 7, p. 95-110, 2001.

NEELY, Andy et al. Designing performance measures: a structured approach. International Journal of Operations \& Production Management, v. 17, Issue 11, p. 1131-1152, 1997.

NIKLASSON, Lars. State, market and oligarchy in higher education. A typology and an outline of the debate. Higher Education Management, v. 7, n. 3, p. 345-353, Nov. 1995.

OECD. Higher education management, v. 13, n. 2, p. 1-129, July 2001.

RODRÍGUEZ PRIETO, B.; ÁLVAREZ PÉREZ, M. Mejora de la gestión en las administraciones públicas: la reingeniería de procesos y las herramientas de workflow. Auditoría Pública, n. 26, p. 89-93, abr. 2002.

SPORN, B. Adaptive university structure: an analysis of adaptation to socioeconomic environments of US and European universities. London: Jessica Kingsley Publishers, 1999. (Higher Education Policy Series 54)

Margarida Mano é professora auxiliar da Faculdade de Economia da Universidade de Coimbra. E-mail: mimano@fe.uc.pt.

Maria da Conceição da Costa Marques é professora coordenadora do Instituto Superior de Contabilidade e Administração de Coimbra. E-mails: mmarques@iscac.pt; mcc@ci.uc.pt. 